MIDPI

sciforum

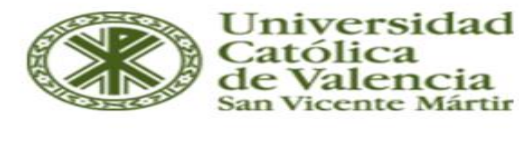

A $>$ International > About us

International
NIXMSM-07: Iberoamerican Workshop on Model. and Simulation Methods, Valencia, Spain, 2021

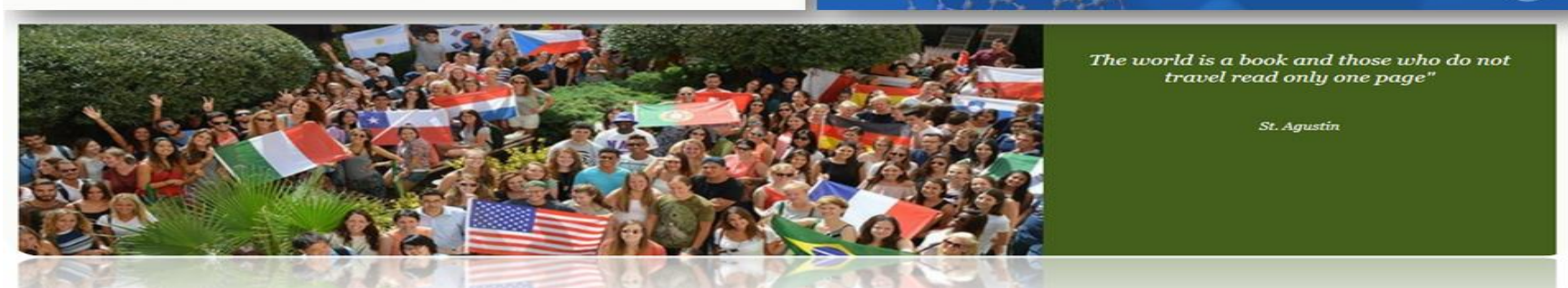

\title{
Phelan-McDermid Syndrome: The prevalence of a rare disease in Spain
}

\section{Eraci Drehmer ${ }^{1}$, Bárbara Gómez ${ }^{2}$, Sandra Carrera-Juliá2 ${ }^{2}$,Mari Ángeles Navarro ${ }^{3}$,} María Jesús Vega ${ }^{4}$, Francisca Sempere ${ }^{2}$, Mari Luz Moreno ${ }^{4 *}$

${ }^{1}$ Department of Health Sciences, Universidad Católica de Valencia San Vicente Mártir, C/Ramiro de Maeztu, 14. 46900 Torrente, Valencia, Spain.

${ }^{2}$ Department of Nutrition and Dietetics, Universidad Católica de Valencia San Vicente Mártir, C/

Quevedo, 2. 46001 Valencia, Spain

${ }^{3}$ Department of Basic Sciences, Universidad Católica de Valencia San Vicente Mártir, C/Ramiro de Maeztu, 14. 46900 Torrente, Valencia, Spain.

${ }^{4}$ Department of Physiology, Universidad Católica de Valencia San Vicente Mártir, C/Ramiro de Maeztu, 14. 46900 Torrente, Valencia, Spain.

\section{Graphical Abstract}

\begin{abstract}
.
Phelan-McDermid Syndrome (PMS) is a rare genetic condition caused by a deletion of the terminal end of chromosome 22 in the 13.3 region, as well as, by point mutations within SHANK3 gene. The most characteristic clinical symptom is global developmental delay, absent or severely delayed speech, hypotonia and autism spectrum disorder. The syndrome is underdiagnosed and its real incidence remains unknown, but more than 2,000 cases have been reported worldwide. In the present investigation patients diagnosed with PMS for twelve years were recruited
\end{abstract}




\section{PUELAN MCDERMUD SYNDROME}

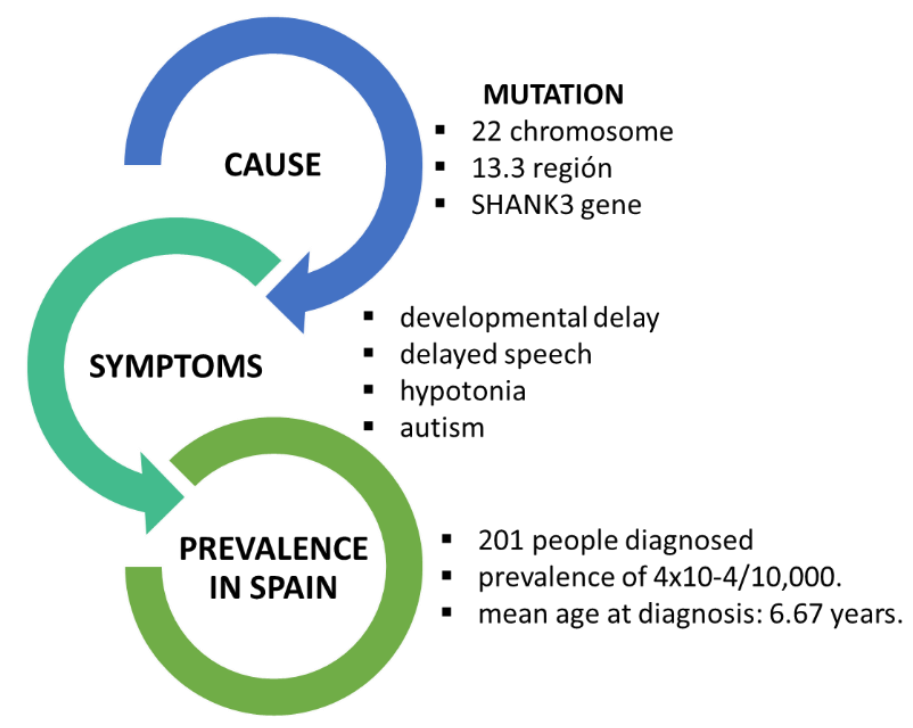

throughout the Spanish territory. The clinical patient information was obtained from the referral doctors using two standardized questionnaires completed with data from the medical reports and the interview with the parents. The molecular diagnosis of the disease was carried out using different formats of microarrays. Data were processed using Microsoft Excel and Statgraphics Centurion XVII.

Currently, there are 201 people diagnosed with PMS in Spain with a prevalence of $4 \times 10-4 / 10,000$. The community with the most diagnosed patients is Madrid and there are no significant differences in terms of sex. The mean age at diagnosis is around 6.67 years. Therefore, the prevalence of the disease in Spain is very low, and it can be stated that it is very likely that there are more people with this syndrome in the population.

\section{References}

1. Kim YM, Choi IH, Kim JS, Kim JH, Cho JH, Lee BH et al. Phelan-McDermid syndrome presenting with developmental delays and facial dysmorphisms. Korean J Pediatr. 2016; 59 (Suppl 1): S25-S28.

2. Anderlid BM, Schoumans J, Anneren G, et al. FISH-mapping of a 100-kb terminal 22q13 deletion. Hum Genet 2002; 110: 439-443.

3. Tabet A-C, Rolland T, Ducloy M, L vy J, Buratti J, Mathieu A, et al. A framework to identify contributing genes in patients with Phelan-McDermid syndrome. npj Genomic Medicine 2017; 2 (1).

4. Gómez Taylor B, Moreno Sancho ML, Drehmer Rieger E, Carrera Julia S, Nevado J, Sempere Ferre F. Prevalencia del síndrome de Phelan-McDermid en España. Rev Esp Salud Pública. 2020; 94: e202012121.

Nereis: https://www.ucv.es/investigacion/publicaciones/catalogoderevistas/revistanereis 